\title{
GARGOYLISM
}

\section{A REVIEW OF THE PRINCIPAL FEATURES WITH A REPORT OF FIVE CASES}

BY

\author{
J. L. HENDERSON, M.D., F.R.C.P.E.
}

Lecturer, Department of Child Life and Health, University of Edinburgh

\section{WITH AN ADDENDUM REPORTING AN ADDITIONAL CASE OF GARGOYLISM}

BY

\author{
R. W. B. ELLIS, M.D., F.R.C.P.
}

The illuminating work of several authors during the last decade has led to a more general recognition of this rare familial syndrome. Briefly, the disease is a form of congenital chondro-osteodystrophy in which the deformities of the head, trunk and limbs are associated with mental defect, corneal clouding and hepatosplenomegaly. Owing to the uncertain pathogenesis, ' Gargoylism,' the colloquial term introduced by Ellis, Sheldon and Capon (1936), would appear preferable to the numerous other designations which have been suggested. It has become generally accepted in this country, but 'Hurler's Syndrome,' 'Polydystrophy-Hurler Type,' 'Chondro-osteodystrophy-Hurler Type ' and 'Dysostosis Multiplex-Hurler Type,' amongst others, are terms usually preferred by continental authors. The impressions resulting from a survey of the literature have been embodied in a short account of the principal features of the disease. Records of fifty-seven cases have been found, although satisfactory details are lacking in nine instances. Doubtless, a number of cases will have been missed owing to the lack of a standardized nomenclature. A further five cases are now presented.

This paper is intended primarily as a tribute to the late Dr. John Thomson of Edinburgh, who was probably the first to recognize the condition as a disease sui generis. Four of the five cases now presented were under his care at the Royal Edinburgh Hospital for Sick Children, the first of the McL. trio as long ago as 1900 . When a younger sibling with similar features came to his notice in 1908 he realized he was dealing with a disease which had no counterpart in the literature and called it 'Johnny McL___s disease' after the first case. It is a pity he did not report these cases, as he would have been the first to draw attention to the disease and would have advanced its more general recognition 
by a generation, but it was typical of the man to refrain from publishing work which he considered immature. It is of interest to recall, however, that Dr. Thomson demonstrated the fourth case of this series at a meeting of the Edinburgh-Glasgow Paediatric Club in 1924, when he also gave an account of the salient features of the disease.

\section{Cases reported in the literature}

Adequately authenticated cases have been reported as follows:

\begin{tabular}{|c|c|c|}
\hline YEAR & AUTHORS & NO. OF CASES \\
\hline 1907 & Berkhan & 1 \\
\hline 1917 & Hunter & 2 \\
\hline 1919 & Hurler & 2 \\
\hline 1921 & Jewesbury and Spence & 1 \\
\hline 1924 & Nonne & 3 \\
\hline 1925 & Putnam and Pelkan & 1 \\
\hline 1931 & Helmholz and Harrington & 4 \\
\hline$"$ & Ruggles & 3 \\
\hline 1933 & Binswanger and Ullrich & 2 \\
\hline 1934 & Sheldon & 1 \\
\hline, & Ellis & 1 \\
\hline , & Poynton, Lightwood and Ellis & 1 \\
\hline ," & Davis and Currier & 2 \\
\hline , & Jansen & 1 \\
\hline 1935 & Cockayne & 1 \\
\hline 1936 & Cockayne & 2 \\
\hline , & de Lange and Woltring & 2 \\
\hline 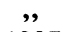 & Ellis, Sheldon and Capon & 4 \\
\hline 1937 & Ellis & 1 \\
\hline$"$ & Bokkel Huinink & 1 \\
\hline ", & Liebenam & 1 \\
\hline ," & Ashby, Stewart and Watkin & 1 \\
\hline ", & Nordmann & 2 \\
\hline 1938 & Ellis & 1 \\
\hline$"$ & Kressler and Aegerter & 1 \\
\hline ," & Bindschedler & 2 \\
\hline , & Slot and Burgess & 1 \\
\hline 1939 & Engel & 2 \\
\hline 1940 & Gillespie and Siegling & 1 \\
\hline
\end{tabular}

Inadequately authenticated cases have been reported as follows:

\begin{tabular}{clc} 
YEAR & \multicolumn{1}{c}{ AUTHORS } & NO. OF CASES \\
1931 & Helmholz and Harrington & 2 \\
1934 & Davis and Currier & 1 \\
1936 & Ellis, Sheldon and Capon & 2 \\
1937 & Ashby, Stewart and Watkin & 2 \\
\#39 & Tombleson & 1 \\
1939 & Höra & 1
\end{tabular}

There is little doubt of the validity of these cases, but the data are insufficient for their inclusion in a review.

The work of Ellis, Sheldon and Capon (1936), who reviewed the literature along with their own series of cases and analysed the clinical features of the disease, constitutes a noteworthy milestone. Ashby, Stewart and Watkin (1937), in the following year, were the first to describe the pathology, their account of the neuropathology being admirable. The full pathological report by Kressler and Aegerter (1938), a year later, was a valuable contribution, as they were the first to demonstrate widespread extracerebral deposits of lipoid 
in a typical case of the disease. In addition to the above, the literature has been reviewed by the following authors: Liebenam (1937), Ellis (1937b), Bindschedler, Rodier and Heintz-Bertsch (1938) and Engel (1939). Several of the cases mentioned in this paper have not been included in previous reviews.

\section{Clinical features}

Bone changes and general appearance. Growth is usually retarded from an early age. Most of the cases were said to have grown normally for the first year. Liebenam's (1937) patient is of particular interest in this respect, as her twin sister was normal. The mother first noticed a slowing down in the rate of growth at the age of two-and-a-half years; at six to seven years growth ceased. Dwarfing is always severe in those which survive childhood.

THE HEAD. The cranium is nearly always enlarged and, unlike the face, its conformation is variable. Scaphocephaly is the principal type, while brachycephaly is almost as common. Bulging of the squamous part of the temporal bones often occurs and oxycephaly is occasionally found. Hydrocephalus is a frequent complication. Bony ridges along the suture lines and unduly prominent supra-orbital ridges sometimes occur. Closure of the anterior fontanelle is always greatly delayed.

The grotesque facial appearance is typical and one of the most constant features of the disease. The nasal bridge is flat and wide and the nostrils are often turned forwards. The mandible is frequently broad and heavy and the teeth widely spaced, irregular and poorly developed. Dentition commenced at the normal time in about half of the cases, but in others was greatly delayed. The lips are usually thick and the large tongue, often fissured, lies well forward in a slightly open mouth, sometimes actually protruding a little. Full cheeks are the rule and they often have a ruddy hue. The ears usually appear to be unduly low-set and occasionally are enlarged. Coarse, dark eyebrows frequently add to the uncanny appearance, but the hair is usually fine and silky.

The sella turcica was radiographed in about half of the cases and with a few exceptions was considerably enlarged though relatively shallow.

THE TRUNK. The neck is usually short, the head appearing to be planted on the shoulders. The chest is seldom well formed, but gross malformations such as occur in Morquio's disease have not been observed. Flaring of the costal margins and minor degrees of pigeon-breast are frequently seen. X-rays show considerable broadening of the ribs. Dorsolumbar kyphosis is seldom absent and is caused by a dysplasia of one or more of the upper lumbar vertebrae. The affected vertebrae are notably small, with a flattened or wedge-shaped body which frequently bears an anterior hook-like process (see Addendum, fig. 3).

The abdomen is usually enlarged, often grossly. Umbilical hernia is present in the majority of cases and inguinal hernia is common.

THE LIMBS. The most conspicuous features are the relatively short arms and impaired mobility of the joints with slight permanent semiflexion. This impaired movement gives these patients an ungainly and sometimes a slightly crouching attitude and a stiff, clumsy gait. The scapulae usually lie abnormally high and Engel (1939) believes that Sprengel's deformity is a characteristic 
feature of the syndrome. Movement at the shoulder is very restricted on abduction of the arms, the scapulae being rotated into the axillae. The broad, short claw-hands are conspicuous. In the legs coxa valga, genu valgum and pes planus have been observed on several occasions.

The radiological changes are more striking in the limbs than elsewhere. The bones are thickened and roughly formed, the latter being most apparent in the neighbourhood of joints. The humeral and femoral heads are irregular and flattened and the glenoid fossae and acetabula unduly shallow. Irregular epiphyseal ossification is a constant feature, osteosclerotic and rarefied patches often being seen. Carpal ossification is retarded.

Mental DEFECT. Amentia is one of the most characteristic features of the disease. The majority of the published cases were severely defective. Nine cases gave an impression of normality (Hunter, 1917; Nonne, 1924; Cockayne, 1936; Liebenam, 1937; Orr-Ewing cited by Ashby et al., 1937) and three others of only very slight mental impairment (Hunter, 1917; Davis and Currier, 1934). The three sisters described by Nonne were all 'among the best' at school. Two of these girls were twins. The thirteen-year-old girl described by Liebenam displayed more than average intelligence at school and did as well as her normal twin sister, but unlike the latter, who was jolly and sociable, she was serious, shy and sensitive.

In several instances a falling off in the rate of mental development was observed after the first year or two of life, and at a later stage dementia occurred in a few cases. Fits are not a feature of the condition.

Corneal clouding. This is another salient feature, but it is not invariably present. The clouding is usually congenital and diffuse, giving the corneae a ground-glass appearance, but seldom involves the superficial layers. Occasionally there are multiple discrete opacities. Hitherto, corneal clouding has been regarded by most authors as an essential criterion in the diagnosis of this disease. It did not occur in the cases described by Cockayne (1936) or in those by Hunter (1917) and Nonne (1924). Although no corneal clouding was noted in the second case described by Ashby et al. the neuropathology was typical of the disease and, as the state of the pupils was mentioned, it is unlikely that any corneal clouding could have been missed. Buphthalmos occurred in a few of the cases. It was a feature of the two brothers described by Davis and Currier (1934), who also suffered from optic atrophy and were almost blind.

Hepatosplenomegaly. Enlargement of the liver and spleen occurs in the majority of cases and occasionally is extreme. It does not occur in all cases, however, as demonstrated in the two autopsies reported by Ashby et al.

Other features. Rhinitis, resulting from the nasal malformation, occurs in the majority of cases and recurrent mucopurulent rhinorrhoea is often profuse. Recurrent otorrhoea and respiratory catarrh are common secondary disturbances. Deafness was noticed in several of the more intelligent cases and it may have been an undetected feature in many of those with severe amentia. The muscles are poorly developed and weak. Hypertrichosis is a common feature. A rather leathery skin occasionally occurs. Retarded sexual development was a feature in four of the five cases which had passed the age of puberty 
and was still apparent at the age of twenty-three years in the twins described by Nonne (Cockayne, 1936). Congenital malformation of the heart was detected in two cases, and spina bifida, club-foot and cervical rib were each recorded on one occasion. Engel (1939) in his two cases found a considerable decrease in the basal metabolic rate and hypothalamic dysfunction was revealed by the impairment of water secretion as estimated by Hoff's functional test.

In both families described in this paper the affected infants were much larger at birth than their healthy siblings. Other authors have also drawn attention to this fact. Death usually intervenes before the age of ten years, but several of the recorded cases lived longer and two survived for more than twenty years. The period of survival is usually longer in the formes frustes of the disease.

Opportunities for studying subjective phenomena rarely arise owing to the high incidence of mental defect. The principal complaints of Liebenam's patient, whose twin sister was normal, were as follows: difficulty in moving most of the joints, especially in bending down, going upstairs, raising arms to the horizontal and chewing hard food; pains in the back and supra-orbital headache; poor sight and recurrent hearing disturbances; tiredness and dizziness; breathlessness on slight exertion.

\section{Case reports}

The McL. family. The parents are now both aged sixty-four years and appear to be healthy. There is no consanguinity. The father is the second of eleven children ; the tenth, a girl, did not walk until she was three years of age, but this may have been due to rickets, as she did well at school; the other siblings were normal. The mother is the eldest of eleven children all of whom were apparently normal. So far as the parents are aware, none of their nieces or nephews resembled their own abnormal children, nor are they aware of a similar condition ever having occurred in the family before. There were nine children, as follows:

1 Male. Healthy. Killed in action, aged twenty-two years.

2 Male. Died, ? cause, aged six weeks.

3 Female. Healthy and married. Died, ? cause, aged twenty-two years. A female child died of ? tuberculosis, aged nine years.

CASE 1. 4 Male. Died aged five years.

5 Female. Healthy and married. Has had two children, a girl who died of scalds aged three years and a healthy boy aged three years.

CASE 2. 6 Male. Died aged six years.

7 Female. Healthy; aged thirty-two years. Married recently.

CASE 3. 8 Female. Died aged seven years.

9 Male. Healthy; aged twenty-seven years. Unmarried.

The three abnormal children were all big babies at birth and much larger than the healthy ones.

Case 1. Johnny McL. was admitted to the Royal Edinburgh Hospital for Sick Children on October 27, 1900, aged two-and-a-half years. He died aged five years. 
History. Birth was spontaneous. The child was breast fed; he never learned to stand by himself nor to crawl. Speech never developed beyond baby talk. He could eat a biscuit, but never learned to use a spoon or cup. He was always doubly incontinent. He recognized his own family. No mental deterioration was observed before death. A few fits occurred between the ages of six and twelve months. Teeth were not unduly late in erupting; many soon decayed. The parents first noticed corneal clouding at about three years old, 'something like cellophane came across the eyes' ; this persisted until death, but was not always noticeable. 'Legs were always as thin as straws.' 'He gradually wasted and sank.'

PhySICAL EXAMINATION (aged two-and-a-half years). Not very detailed, as principal case record not available. A dwarf with a large head and a prominent abdomen. Shape and size of cranium not stated. Nasal bridge flat; a heavy breather with a chronic nasal discharge. Cheeks plump. Neck very short. Pigeon-breasted, with splayed out costal margin. Dorsolumbar kyphosis of moderate degree. No data regarding hands or mobility of limbs. Eyes not mentioned. Abdomen protuberant, with an umbilical hernia and large bilateral inguinal herniae; no reference to liver or spleen.

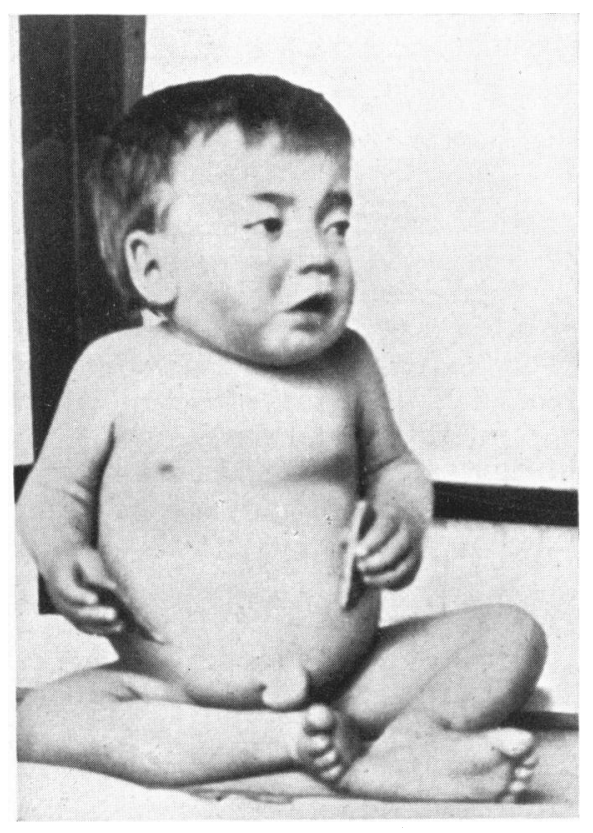

FIG. 1.-CASE 2. C. McL., aged $3 \frac{1}{2}$ years.

Case 2. Charles McL. (fig. 1) was admitted to the same hospital on June 8, 1908, aged three-and-a-half years. He died aged six years.

HISTORY. Birth was spontaneous; the child was breast fed for eighteen months. 'Up to one year was a thriving baby, after that failed to develop as expected.' Walked with the aid of a chair pushed in front of him at three years old, but never walked alone, usually crawled. Speech never developed beyond baby talk. 'When hungry points to the dresser, when thirsty to the well.' Always doubly incontinent. Good tempered. Mentality developed further than in case 1, 'he was a shade cleverer.' No mental deterioration was observed. 
Teething began at nine months, when there was one convulsion; many of the milk teeth decayed early. Parents noticed a corneal haziness which was similar to that seen in case 1 . The child suffered from recurrent nasal discharge and otorrhoea from early infancy. He gradually became very emaciated before death.

Physical examination (aged three-and-a-half years). A dwarfed child weighing $26 \mathrm{lb}$. Head large, circumference $20 \frac{1}{2}$ in.; fontanelle open, area $\frac{1}{2}$ sq. in. Nose broad, constant mucous discharge. Mouth open, with tongue well forward. Cheeks plump. Neck very short. Thorax narrow and pigeonbreasted. Marked dorsolumbar kyphosis. Hands stumpy, with short broad fingers. Sits up in bed with legs crossed and has a vacant expression. Ruddy complexion; skin rather leathery. Eyes appear normal. Abdomen very prominent, with large umbilical hernia and wide diastasis of the recti muscles. Liver palpable one finger-breadth below the costal margin and spleen palpable at costal margin. Mild bronchitis.

Case 3. Jenny McL. was admitted to the same hospital on July 12, 1913, aged two years and three months. She died aged seven years.

History. Birth was spontaneous. Breast fed for eight months. 'A fine plump baby up to a year, after which did not seem to grow until shortly before admission.' Never learned to walk, but crawled about the house. Unlike the two brothers, learned to say a few intelligible words. Learned to use a spoon and cup. Always doubly incontinent. 'Cleverer than the two brothers.' No mental deterioration was observed. Never had fits. Teething began at seven months, but many of the milk teeth decayed early, as in the case of the two boys. No haziness of the eyes was observed by the parents in this case and she was not seen again in hospital. She snored a great deal, and had occasional otorrhoea.

Physical EXAMINATION (aged two years three months). A dwarfed child weighing $21 \frac{1}{4} \mathrm{lb}$. Head ' normal shape,' circumference $19 \frac{1}{2}$ in., fontanelle still open. Nasal bridge broad and sunken. Upper lip prominent. Mouth usually closed, but tends to suck tongue. Ears rather large. Neck short. Chest shows tendency to pigeon-breast with sternum thrown well forward. Slight dorsolumbar kyphosis. Fingers stumpy, particularly the thumbs.

A quiet child; can be induced to smile occasionally. Complexion ruddy; skin rather leathery. Eyes appear normal. Abdomen slightly prominent, with small umbilical hernia. Liver enlarged, with lower border three finger-breadths below costal margin in midclavicular line. Spleen greatly enlarged, with lower border extending four finger-breadths below the costal margin. Heart enlarged with loud basal murmur indicating congenital malformation. X-ray examination of sella turcica failed owing to movement.

The N. family. The parents are first cousins, their mothers being sisters. They are healthy. The mother has seven sisters and one brother, all of whom are healthy and married; they all have families of three to five children who are also healthy. The father is also one of nine children; he has a twin sister with four healthy children, another sibling has one child, four others are married but childless, and two are unmarried. The parents were not aware of abnormal children such as their own ever having occurred in the family before. There were four children as follows:

CASE 4. 1 Male. Died aged six years and four months.

2 Male. Healthy; aged seventeen years.

3 Female. Healthy; aged thirteen years.

CASE 5. 4 Female. Died aged eight years and four months.

The two abnormal children were big babies and weighed $9 \frac{1}{2} \mathrm{lb}$. at birth, whereas the two normal babies weighed $8 \mathrm{lb}$. 
Case 4. James. N. (fig. 2 and 3) was examined at Royal Edinburgh Hospital for Sick Children on June 1, 1921, aged one year and seven months. He died aged six years and four months.

HistORY. The child was born spontaneously and was breast fed for one year. The parents were not concerned about the child until the age of six months, when they were struck by the large size of the head and angulation of the lower spine. There seemed to be little growth after the third year. The

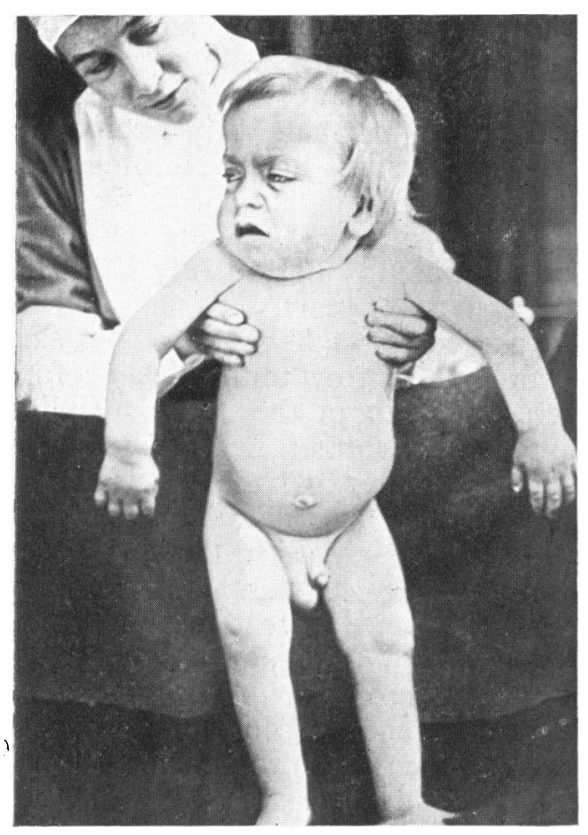

FIG. 2.-CASE 4. J. N., aged $1 \frac{1}{2}$ years.

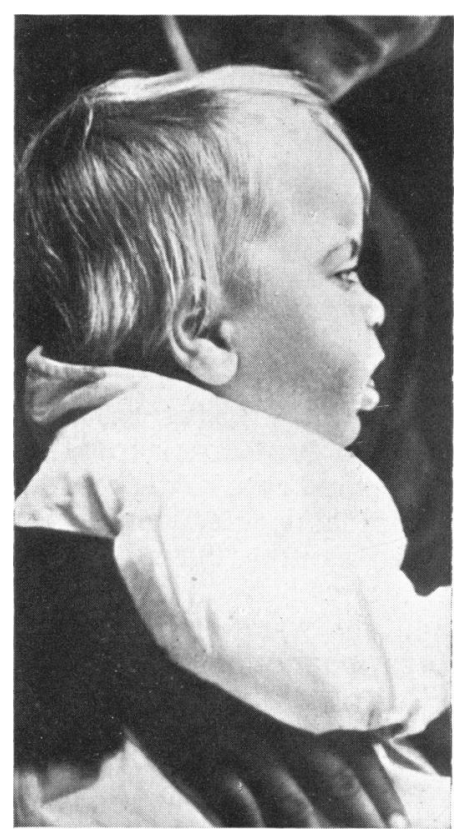

Fig. 3.-CASE 4. Profile of J. N., aged $1 \frac{1}{2}$ years.

child was slow in learning to smile and grip objects. He began to walk at two years, but ceased to do so twenty months before death. He never spoke more than a few words, such as 'motor' and 'horsey,' and called mother 'Terry.' He began to feed himself in the third year, but ceased to do so one year before death. Habits became semi-clean in the third year, but he relapsed about two years before death. He knew where to go for food and drink, and recognized his own family and their friends, but cried when strangers entered the house. Mental deterioration became more pronounced in the last six months of life. He never had any fits.

Teething was greatly delayed and slow, the first two teeth not erupting until well over one year old. Many of the teeth soon decayed. Corneal clouding was first observed at a little over one year old. The brachial stiffness seemed to get worse as time went on. The abdomen was always large. The inguinal hernia was cured by operation at three-and-a-half years. The tongue always protruded from the open mouth and was enlarged and fissured. There was an almost continuous rhinorrhoea, but never any otorrhoea. He spent the last eight months of life in an institution, where he died of 'double pneumonia' aged six years and four months.

Physical eXamination (aged one year seven months). The head is considerably enlarged and the fontanelle still large. Root of nose flat and broad. 
Cheeks plump. Jaw broad and rather heavy. Neck short, the head appearing to be planted on the shoulders. Thorax shows considerable degree of pigeonbreast and flaring of the costal margins. Dorsolumbar kyphosis of moderate degree. Arms short, the stumpy hands being noticeable owing to their semiflexed fingers. Movement at shoulder joints very limited, abduction of arms rotates scapulae into axillae. The child is able to sit up, but the large head is held unsteadily. Both corneae show hazy, ground-glass appearance. The hair is light brown and silky, and the eyebrows bushy; there is hypertrichosis on the upper part of the back. The abdomen is very large, with a large umbilical hernia and a unilateral inguinal hernia. Liver considerably enlarged and spleen very much so, extending almost three finger-breadths below costal margin.

Case 5. Muriel N., was examined at the same hospital on March 27, 1929, aged one year and one month. She died aged eight years and four months.

HisTORY. Birth spontaneous, child was breast fed for seventeen months. Parents first became alarmed at about eight months, when they noticed haziness of the eyes. When called in at that time the family doctor at once recognized the child's close resemblance to case 4 . There was little growth after the first three years, 'fair until then.' The child was slow in taking notice and gripping, and was two years old before she could feed otherwise than by bottle. She began to creep at two years, but never learned to stand nor walk; she could ' run like a hare ' on her knees, but ceased to move about 'after a fall' when five years old. Never spoke a word, nor learned to feed herself. Always double incontinence. Like her brother, she knew her family and was afraid of strangers, but in general the boy was 'the sharper of the two.' The mental state deteriorated during the last three years of life. Never any fits. Teething was greatly delayed, and many of the teeth soon began to decay. The limbs were always very thin. There was chronic snuffles and rhinorrhoea. Mouth was often open, but the tongue not protruded; 'it was rough and rather large.' Ultimately the child became very emaciated, but continued to feed well until she died in sleep, aged eight years and four months. When last seen, two weeks before death, she was extremely weak and emaciated.

PhysiCAL EXAMINATION (aged one year and one month). Head somewhat enlarged, with prominent frontal eminences; anterior fontanelle still large. No teeth. Unable to sit up. Considerable corneal opacity present in both eyes. Liver enlarged, extending two finger-breadths below costal margin, and spleen very large, reaching fully three finger-breadths below costal margin. Apart from the absence of an inguinal hernia and of hypertrichosis, the clinical features were similar to those already described in the case of the brother.

\section{Pathology}

Post-mortem examinations were made on only four of the cases reported in the literature. Unfortunately, the diagnosis was unknown at the time in each one and consequently the investigations were incomplete. Kressler and Aegerter, in the last of these cases, furnished the most complete report, but they regretted their failure to carry out biochemical analyses on the fresh tissues.

Tuthill (1934) was the first to describe the autopsy findings in a case of this disease. The case was one of those reported by Hurler (1919), but he was unaware of this fact and thought the neuropathology typical of the juvenile type of amaurotic family idiocy which was regarded as having unique histological features at that time. The more recent observations of Ashby et al. (1937) and of Kressler and Aegerter (1938) corresponded with those of Tuthill and firmly 
established the fact that the neuropathology of this disease closely resembles that of the juvenile form of amaurotic idiocy. The extreme ballooning of nerve cells and the marked degeneration of their processes which occur in the infantile form of the latter disease were not seen in any of these cases.

A brief account of the principal pathological features as seen in the few reported autopsies will be given below.

The brain. The morbid conditions in the brain were almost identical in all four cases. The convolutional pattern was rather simple. Internal hydrocephalus was found in Tuthill's case.

The cortical nerve cells were sparse, and degenerative changes in the nerve cells were seen throughout the central nervous system. Many were swollen and displayed eccentric nuclei with greatly diminished Nissl substance and conspicuous masses of lipoid matter deposited in the cytoplasm. While occasional disintegrating nerve cells were seen, others showed little, if any, departure from the normal, but appropriate staining methods seldom failed to reveal the presence of the abnormal lipoid deposits. The cell processes were unaltered in the cases of Ashby et al., but some thickening was observed by Kressler and Aegerter. Degenerative changes were more pronounced in the basal ganglia and in the brain stem than in the cortex. Profoundly altered cells were particularly numerous in the optic thalamus, the midbrain, the dentate nucleus, the inferior olives of the medulla and the ventral horns of the spinal cord; but in the optic thalamus the granular deposit in the large cells was coarser and more conspicuous than elsewhere. In the cortex the deeper cell layers were the more severely affected, particularly the medium and large pyramidal cells. Ballooning of the cells was a feature in the prefrontal areas. Unlike Tay-Sach's disease, the cerebellar changes were, for the most part, only slight. Gliosis was a conspicuous feature in the optic thalamus and in the hypothalamus and, to a lesser extent, in the periventricular regions. Elsewhere the increase of glial tissue was only slight.

An extracellular lipoid infiltration was found in certain areas of grey matter, but none was seen in the white matter. Its distribution was principally perivascular and the heaviest deposits were seen in the globus pallidus. Deposits were also seen in the putamen, the caudate nucleus, the optic thalamus, the midbrain and the dentate nucleus. Cortical deposits were confined to the precentral and postcentral areas, and small amounts were also seen in the cerebellar cortex.

The bones. The morbid anatomy of the bones has been mentioned under $\mathrm{x}$-ray appearances. Histological examination of the epiphyseal cartilage has been reported on only two occasions. Kressler and Aegerter found normal ossification and healthy bone growth in their case, and although there were lipoid deposits in most of the tissues, none were found in the bones. Recently, however, Höra (1939) and Elsner, working in Pfaundler's Clinic at Munich, demonstrated histologically a hypoplastic chondrodystrophy in the bones of an affected infant.

Other tissues. Kressler and Aegerter found a widespread lipoid infiltration of the tissues in their case. It was both intra- and extracellular in most situa- 
tions. The heaviest extracerebral deposits were found in the liver, the anterior lobe of the pituitary gland and in the lymph glands, but large amounts of lipoid were also seen in the myocardium and pericardium, the lungs and pleurae, the thymus, the spleen, the testes and the corneae. In the corneae proper the lamellae were widely separated. While pointing out that this might have been an artefact, the author thinks that the spaces were more likely to have been occupied by lipoid matter which had been dissolved out during fixation. There was no evidence of any other pathological process in the corneae. No deposits were seen in the thyroid, the pancreas, the suprarenals, the kidneys, the bones or the bone-marrow.

In addition to the brain Ashby et al. examined the thyroid, the pituitary, the thymus and the suprarenals in their first case and the thyroid and liver in their second case. There was no sign of lipoid deposition in any of these tissues. In neither case was there any hepatic or splenic enlargement. Ellis (1937b) failed to find any evidence of lipoid infiltration in a biopsy examination of the liver and spleen of a typical case with enlargement of these organs.

The anterior lobe of the pituitary gland was considerably enlarged in the two cases in which it was examined. There was a hyperplasia of all three types of cell in both instances, but lipoid infiltration was seen in only one case. It was abundant, and both intra- and extracellular, the largest deposits being seen in the chromophobe cells. The large size of the sella turcica in most of the cases suggests that enlargement of the pituitary gland usually occurs, although the enlargement of the sella may be a manifestation of osseous dysplasia, as suggested by other authors.

The thyroid gland was examined in three cases and it was found to be abnormal in two. In both these cases the structure was consistent with hypothyroidism, one having a foetal structure and the other showing a considerable degree of parenchymatous degeneration and fibrosis. Patients suffering from this disease resemble cretins in a number of ways and not infrequently are diagnosed as such. Several of the reported cases were given courses of thyroid therapy, but they all failed to show any appreciable improvement.

The lipoid deposit. The properties of the lipoid deposits in the brain of their first case were carefully investigated by Ashby et al. They found that the staining reactions of the intracellular and the extracellular deposits were different, those of the intracellular substance having a close resemblance to the staining reactions of the lipoid found in the juvenile type of Tay-Sachs' disease. This intracellular deposit stains with scharlach red in both diseases, but the extracellular only in Tay-Sachs' disease. They also found that the staining reactions and the solubilities of the extracellular deposit failed to correspond with those of any known lipoid, and regretted that it was not present in sufficiently large amounts to permit of its isolation. On the basis of the solubility tests they believed they were dealing with a lipoid consisting mostly of cerebrosides, chiefly phrenosin and kerasin.

The staining reactions of the infiltrating substance in the case reported by Kressler and Aegerter did not correspond with those found in the case of Ashby et al. They were almost consistently negative. 
Comment. Ellis et al. (1936), in discussing Tuthill's findings, were the first to suggest that gargoylism might ultimately prove to be a disorder of lipoid metabolism. This belief appeared to be substantiated by the admirable work of Ashby et al. in the following year. They demonstrated a neuropathology similar to that of Tay-Sachs' disease which was first recognized as a lipoidosis only a few years earlier. The demonstration of widespread extracellular lipoid deposits by Kressler and Aegerter in their typical case appeared to confirm the view that this disease also belongs to the lipoidosis group. There need be no difficulty over the fact that extracerebral lipoid deposits were not found by Ashby et al. in their cases, as variability in the distribution of the lipoid deposits is a characteristic feature of the lipoidoses. The failure of Kressler and Aegerter to confirm the observations of Ashby et al. on the nature of the lipoid may be accounted for by the different methods of fixation employed.

The extracerebral pathology of the disease, apart from the osseous anomalies, cannot be envisaged in its true perspective until more necropsies have been performed. Further, ante-mortem diagnosis should afford opportunities, which have not arisen hitherto, for adequate biochemical analysis of the lipoid deposits.

As suggested by other authors, it seems likely that endocrine dysfunction may contribute to the clinical picture of the disease. The important rôle played by the hypothalamus in metabolic processes has become increasingly evident in recent years. It is acknowledged to play a part in lipoid metabolism, and one wonders what significance the gliosis in that region may have in these cases. The hypothalamic disturbances are probably connected with the changes seen in the pituitary and thyroid glands and these, in turn, with some of the clinical features of the disease such as the chondrodystrophy and dwarfism. However, Ellis's (1937b) remark that ' it is as yet too early to assess the part played by the thyro-pituitary mechanism in the production of the syndrome' is still applicable.

\section{Etiology}

Although males predominate there is no significant difference in the sex incidence. The available evidence indicates that the condition is recessively inherited. A cousin of the boy reported by Jewesbury and Spence (1921) was similarly afflicted and five instances of consanguinity in the parents have been recorded. The parents in the last two cases of this series were first cousins, as in an unpublished case mentioned by Cockayne (1936), while the parents of the three sisters described by Nonne (1924) and in one of the cases published by Binswanger and Ullrich (1933) were second cousins. The paternal grandparents of the two brothers recorded by Hunter (1917) were first cousins.

The occurrence of the disease in a pair of siblings has been recorded on nine occasions as follows: Hunter (1917), Helmholz and Harrington (1931), Ellis et al. (1936), Cockayne (1936), de Lange and Woltring (1936), Bindschedler (1938), Engel (1939) and cases 4 and 5 of this series. An unpublished instance was mentioned by Ashby et al. (1937). The disease has been observed in three members of a family on four occasions. Nonne (1924) reported its occurrence in three sisters, two of whom were twins. A sister of the two brothers reported 
by Davis and Currier (1934) appears to have been similarly affected. Three siblings in a group of cases described by Ruggles (1931) as examples of Morquio's disease are now regarded as belonging to this syndrome. Finally, the first three cases of this series were all born of the same parents. The five cases of the present series thus belonged to only two families. It is apparent that the disease has a high familial incidence, as this was a feature in thirty-two of the sixty-two cases mentioned in this paper.

The available evidence, though fragmentary, would appear to justify the view of several of the more recent authors that gargoylism should be grouped with the lipoidoses. The other diseases comprising this group are Gaucher's. disease, Schüller-Christian's disease, Niemann-Pick's disease and Tay-Sach's disease. In all five conditions the familial incidence is significantly high and it would seem that all are recessively inherited. Further, although some cases of Gaucher's disease and Schüller-Christian's disease may not become manifest until adult life, they all predominate in early childhood and are essentially congenital.

\section{Conclusion}

Several of the recorded cases of gargoylism have been regarded as examples of Morquio's disease by their authors. In the latter disease only skeletal changes occur, and whereas the head is normal, the deformities of the trunk and limbs are much more extreme than in gargoylism. There is no mental defect in Morquio's disease. It is not surprising that gargoylism is frequently mistaken for cretinism.

Although a preference has been expressed for the name ' gargoylism,' there are doubtless some who would prefer an eponymic term in accordance with the precedence established in the case of the other lipoidoses. In such an event the name of 'Hunter-Hurler's Disease' is suggested. Gertrud Hurler, who published an account of two cases from Pfaundler's Clinic at Munich in 1919, is generally regarded as being the first to describe the disease, hence the term 'Hurler's Disease.' It has been overlooked, however, that two years earlier Hunter gave an excellent description of the condition in two brothers, and he pointed out that he regarded it as a new disease to which he could not find any reference in the literature. It is regrettable to confuse the question of nomenclature further, but in the absence of universal standardization it seems justifiable to make this suggestion, not only because of the wish to do honour where it is due, but also for the sake of accuracy.

\section{Summary}

A short account of the features of gargoylism has been given.

Fifty-seven cases recorded in the literature have been reviewed. Five additional cases are now presented.

The disease is congenital, and the principal clinical features are chondroosteodystrophy with extreme dwarfism, mental defect, corneal clouding and hepatosplenomegaly. 
The most constant pathological changes are found in the osseous and nervous systems. The bones are thickened and many of them display characteristic deformities. In the brain there are widespread degenerative changes in the nerve cells with intra- and extracellular lipoid deposits. Lipoid deposits may occur in the corneae, liver, spleen and other tissues.

The disease is recessively inherited and there is a high familial incidence. There have been five instances of consanguinity in the parents.

The available evidence, although fragmentary, offers a considerable amount of support for the view expressed by several authors within the last few years that the disease should be grouped with the congenital disorders of lipoid metabolism. The relationship of the chondro-osteodystrophy to the other morbid features is obscure.

Thanks are due to Professor Charles McNeil for the interest he has taken in this work. He was associated with the late Dr. John Thomson for many years and knew all the patients of this series except the first.

\section{REFERENCES}

Ashby, W. R., Stewart, R. M., and Watkin, J. H. (1937). Brain, 60, 149.

Berkhan, O. (1907). Arch. Anthrop., Braunschw., 34, 8.

Bindschedler, J. J. (1938). Bull. Soc. Pédiat., Paris, 36, 571.

—_, Rodier, J. M., and Heintz-Bertsch, Mme. (1938). Rev. franç. Pédiat., 14, 116.

Binswanger, E., and Ullrich, O. (1933). Z. Kinderheilk., 54, 699.

Bokkel Huinink, A. ten (1937). Maandschr. kindergeneesk., 6, 449.

Cockayne, E. A. (1935). Proc. roy. Soc. Med., 28, 1067.

- (1936). Ibid., 30, 104.

Davis, D. B., and Currier, F. P. (1934). J. Amer. med. Ass., 102, 2173.

Ellis, R. W. B. (1934). Proc. roy. Soc. Med., 27, 1022.

- (1937a). Ibid., 30, 158.

_- (1937b). ' Gargoylism' : Brit. Encyclopaedia Med. Practice, 5, 496.

- (1938). Proc. roy. Soc. Med., 31, 770.

—, Sheldon, W., and Capon, N. B. (1936). Quart. J. Med., 29, 119.

Engel, D. (1939). Arch. Dis. Childh., 14, 217.

Gillespie, J. B., and Siegling, J. A. (1940). J. Bone Jt. Surg., 22, 171.

Helmholz, H. F., and Harrington, E. R. (1931). Amer. J. Dis. Child., 12, 793.

Höra, J. (1939). Virchows Arch., 305 ii, 298.

Hunter, C. (1917). Proc. roy. Soc. Med., 10 i, 104.

Hurler, G. (1919). Z. Kinderheilk., 24, 220.

Jansen, M. (1934). Z Z orthop. Chir., 61, 253.

Jewesbury, R. C., and Spence, J. C. (1921). Proc. roy. Soc. Med., 14, 27.

Kressler, R. J., and Aegerter, E. E. (1938). J. Pediat., 12, 579.

de Lange, C., and Woltring, L. (1936). Acta Paediatr., Stockh., 29, 71.

Liebenam, L. (1937). Z. Kinderheilk., 59, 91.

Nonne, M. (1924). Dtsch. Z. Nervenheilk., 83, 263.

Nordmann, J. (1937). Bull. Soc. Ophtal. Paris, 49, 256.

Poynton, F. J., Lightwood, R. C., and Ellis, R. W. B. (1934). Proc. roy. Soc. Med., 27, 1025.

Putnam, M. C., and Pelkan, K. F. (1925). Amer. J. Dis. Child., 29, 51.

Ruggles, H. E. (1931). Amer. J. Roentgenol., 25, 91.

Sheldon, W. (1934). Proc. roy. Soc. Med., 27, 1003.

Slot, G., and Burgess, G. L. (1938). Ibid., 31, 1113.

Tombleson, J. B. L. (1937). Ibid., 30, 1070.

Tuthill, C. R. (1934). Arch. Neurol. Psychiat., Chicago, 32, 198. 